\title{
EFEITO DO PÓLEN NAS CARACTERÍSTICAS FÍSICAS E FISIOLÓGICAS DE SEMENTES DE MAMÃO ${ }^{1}$
}

\author{
GABRIELA NEVES MARTINS², MESSIAS GONZAGA PEREIRA ${ }^{3}$, ROBERTO FERREIRA DA SILVA ${ }^{4}$, \\ ANNA CHRISTINA SANAZÁRIO DE OLIVEIRA ${ }^{5}$, FRANCELI DA SILVA ${ }^{6}$
}

\begin{abstract}
RESUMO - A ocorrência do fenômeno xênia, considerado como o resultado do cruzamento que se manifesta na primeira geração da planta mãe, há muito é conhecida. Entretanto, pouco é conhecido a respeito da contribuição do efeito do pólen no comportamento das sementes de mamão. Objetivou-se neste trabalho, avaliar a influência do pólen nas características físicas e fisiológicas das sementes de mamão. As sementes utilizadas foram provenientes de frutos dos grupos Solo e Formosa, oriundos de polinização manual, correspondente aos seguintes tratamentos: T1- Solo autofecundado; T2 Formosa autofecundado; T3 - Solo x Formosa; T4 - Formosa x Solo; T5 - T3 autofecundado; T6 - T4 autofecundado. Foram realizadas as seguintes determinações e testes: número de sementes por fruto, tamanho da semente, peso de mil sementes, testes de germinação, primeira contagem, envelhecimento acelerado, comprimento da radícula, hipocótilo e teste de frio. O delineamento experimental utilizado foi inteiramente casualizado com quatro repetições, sendo as médias comparadas pelo teste de Tukey a $5 \%$ de probabilidade. Não se verificou efeito da origem do pólen nas características físicas das sementes. Para qualidade fisiológica das sementes não foi possível avaliar o efeito da xênia, uma vez que, observou-se a manifestação precoce da heterose.
\end{abstract}

Termos para indexação: Carica papaya L., qualidade fisiológica, xênia

\section{EFFECT OF THE POLLEN IN THE PHYSICAL AND PHYSIOLOGICAL CHARACTERISTICS OF THE PAPAYA SEEDS}

\begin{abstract}
The occurrence of the xenia phenomenon, considered the result of the crossing that is manifested in the first generation of the mother plant, has been known for many years. However, little is known regarding the contribution of the effect of the pollen to papaya seed performance. The objective of this study was to evaluate the influence of pollen on the physical and physiological characteristics of papaya seeds. The seeds used in the study were produced from hand pollinated fruits of the groups Solo and Formosa, corresponding to the following treatments: T1 - selfed Solo; T2 - selfed Formosa; T3 - Solo x Formosa; T4 - Formosa x Solo; T5 - Fruits proceeding from selfed T3; T6 - Fruits proceeding from selfed T4. The following determinations and tests were carried out: fruit weight, number of seeds per fruit, seed size, weight of a thousand seeds, seed germination,
\end{abstract}

${ }^{1}$ Submetido em 22/10/2007. Aceito para publicação em 05/05/2008. Parte da Tese de doutorado do primeiro autor apresentada a UENF.

${ }^{2}$ Pesquisadora CNPq/UFRB, Centro de Ciências Agrárias, Ambientais e Biológicas, UFRB, Cruz das Almas - BA. gabneves@hotmail.com

${ }^{3}$ Prof. Associado, Laboratório de Melhoramento e Genética Vegetal, UENF, Campos dos Goytacazes - RJ. messias@uenf.br
${ }^{4}$ Prof. Titular, Laboratório de Fitotecnia, UENF, Campos dos Goytacazes - RJ.roberto@uenf.br

${ }^{5}$ Pós graduanda em Produção Vegetal, UENF, Campos dos Goytacazes RJ. kisanazario@yahoo.com.br

${ }^{6}$ Prof. Adjunta, Centro de Ciências Agrárias, Ambientais e Biológicas, UFRB, Cruz das Almas - BA. francelisilva@yahoo.com.br 
first count, accelerated aging, radicle and hypocotyl lengths, and cold test. A randomized complete block design was used with four replications and the means were compared by the Tukey test at $5 \%$ probability. No effects of the origin of the pollen were verified on the seed physical characteristics. The effect of xenia on the seed physiological quality could not be assessed because a premature manifestation of heterosis was observed.

Index terms: Carica papaya L., physiological quality, xenia

\section{INTRODUÇÃO}

Xênia é originário do grego "xenos", que significa "um estranho ou hóspede" (Denney, 1992). O fenômeno de xênia pode ser considerado como o efeito do pólen no embrião e endosperma, alterando características genéticas e proporcionando mudanças qualitativas e quantitativas (Andrade e Pereira, 2005), características estas, que se manifestam na geração da planta-mãe (Mercer et al., 2002). Segundo vários autores (Denney, 1992; Bullant e Gallais, 1998; Pereira, 2003), o fenômeno xênia pode afetar o peso do pericarpo, mesocarpo, endosperma ou do embrião, como também na forma, cor, textura, peso, composição química e tempo de desenvolvimento da semente.

De acordo com Freytag (1979), citado por Pereira (2003), quando plantas recebem pólen estranho, esse pode modificar geneticamente a semente e o endosperma, proporcionando um aumento na produção de hormônios em razão da presença de genes favoráveis ou dominantes, com reflexos no peso, tamanho, forma e outros caracteres das sementes.

Crane e Iwakiri (1980) observaram efeito xênia em pistache, mostrando que, dependendo do tipo de pólen utilizado, a semente pode ser modificada.

O efeito do pólen também foi observado no peso da semente de avelã em dois anos de estudos onde foram avaliados os efeitos da xênia. Observou-se que a mistura do pólen de dois cultivares aumentou o peso da semente quando comparado aos de autofecundação (Rahemi e Mojamad, 2001).

A manifestação do efeito xênia nos caracteres relacionados ao endosperma e ao embrião tem sido relatado em várias pesquisas (Davarynijad et al., 1994; Seka e Cross, 1995a; Bullant et al., 2000). De acordo com Kiran e Wicks (1990), citado por Seka e Cross (1995b), verifica-se que o peso médio de grãos de milho provenientes de cruzamento pode superar os de autofecundação em até $16 \%$ e é variável com as linhagens e/ou híbridos envolvidos no cruzamento.
Kiesselbach (1926), citado por Mercer et al. (2002), mostrou aumento de $35 \%$ na produção de milho utilizando cruzamento sweet $\mathrm{x}$ dent quando comparado com sweet $\mathrm{x}$ sweet. Desse modo, a manifestação de xênia pode alterar o desempenho de uma determinada linhagem ou híbrido, dependendo do polinizador utilizado.

Mercer et al. (2002) observaram que o efeito de xênia na cultura do milho contribuiu com o incremento no peso dos grãos, porcentagem de germinação e peso seco das plântulas. Resultados semelhantes foram relatados por Tsai e Tsai (1990) e Bullant e Gallais (1998).

Os resultados encontrados na literatura mostram que os efeitos de xênia ocorrem em cruzamentos específicos, ou seja, quando há uma combinação específica de genes que se completam. Teoricamente, embora se admita a grande importância da capacidade específica de combinação para manifestação de tais efeitos, é possível esperar que sejam encontrados genótipos com alta capacidade geral de combinação para o fenômeno xênia.

Praticamente nada se conhece sobre a existência da xênia em sementes de mamão. Esclarecimentos do fenômeno poderiam ser úteis na seleção dos genitores de híbridos, na obtenção de sementes de maior qualidade.

Objetivou-se com este trabalho, esclarecer a existência do fenômeno xênia em sementes de mamão, o que poderá auxiliar neste caso específico na produção de sementes de alta qualidade do híbrido UENF/Caliman 01 e na avaliação da qualidade fisiológica de sementes de um banco de germoplasma in vivo.

\section{MATERIAL E MÉTODOS}

O experimento foi conduzido no Setor de Tecnologia e Produção de Sementes do Centro de Ciências e Tecnologias Agropecuárias, da Universidade Estadual do Norte Fluminense Darcy Ribeiro, em Campos dos Goytacazes, RJ. Os frutos para extração das sementes foram provenientes da 
Empresa Caliman Agrícola, em Linhares, ES.

As sementes utilizadas foram provenientes de frutos oriundos de polinização manual, colhidos no estádio II de maturação e os tratamentos foram os seguintes:

- Tratamento 1 (S) - Frutos de plantas do grupo Solo, Sunrise Solo 72/12, proveniente de autofecundação;

- Tratamento 2 (F) - Frutos de plantas do grupo Formosa, JS12, proveniente de autofecundação;

- Tratamento 3 (S x F) - Frutos provenientes do cruzamento: genitor feminino do grupo Solo $\mathrm{x}$ genitor masculino Formosa (semente $\mathrm{F}_{1}$ );

- Tratamento 4 (F x S) - Frutos provenientes do cruzamento: genitor feminino Formosa $\mathrm{x}$ genitor masculino Solo (semente $\mathrm{F}_{1}$ recíproca);

- Tratamento $5\left(\mathrm{~F}_{2-\mathrm{S} \times \mathrm{F}}\right)$ - Frutos provenientes da autofecundação de plantas oriundas do tratamento 3 (semente $\mathrm{F}_{2}$ );

- Tratamento $6\left(\mathrm{~F}_{2-\mathrm{F} \times \mathrm{S}}\right)$ - Frutos provenientes da autofecundação de plantas oriundas do tratamento 4 (semente $\mathrm{F}_{2}$ recíproca).

A extração das sementes após o amadurecimento completo dos frutos foi realizada manualmente, utilizando uma peneira e escova de cerdas plásticas para a remoção completa da sarcotesta, e foram secas em secador de leito fixo, a uma temperatura de $38^{\circ} \mathrm{C}$, até atingirem teor de umidade entre $7 \%$ e $8 \%$. As avaliações referentes à qualidade fisiológica das sementes foram realizadas imediatamente após o beneficiamento das sementes.

As determinações realizadas foram: número de sementes por fruto, peso de mil sementes, tamanho da semente (comprimento e largura) e teor de água. A qualidade fisiológica das sementes, correspondente aos tratamentos foi avaliada pelos testes: germinação; primeira contagem; comprimento da radícula e do hipocótilo; envelhecimento acelerado; e teste de frio, descritos a seguir.

Número de sementes por fruto: para a determinação do número de sementes por fruto foram contadas as sementes de pelo menos 10 frutos de cada tratamento.

Peso de mil Sementes: determinado pela contagem ao acaso, de oito subamostras de 100 sementes, as quais foram pesadas, sendo os valores do peso de mil sementes expressos em gramas, com uma casa decimal, conforme Brasil (1992).

Tamanho das sementes: para a determinação do comprimento e da largura das sementes com maior exatidão foi utilizado o software ImageJ, versão 1,32 (ImageJ, 2009). Os resultados foram expressos em $\mathrm{cm}$.

Teor de água: determinado segundo as prescrições das
Regras para Análise de Sementes, utilizando-se duas subamostras de $5 \mathrm{~g}$ de sementes, pelo método de estufa a $130^{\circ} \mathrm{C}$ por 1 hora; o teor de água das sementes foi expresso em porcentagem de base úmida (Brasil, 1992).

Teste de germinação: foi montado de acordo com as prescrições das Regras para Análise de Sementes (Brasil, 1992) com algumas modificações. Foram utilizadas quatro subamostras de 50 sementes por repetição, em rolo de papel germiteste, umedecido com água destilada, na proporção de 2,5 vezes o peso do papel; os rolos foram colocados no interior de sacos de polietileno transparente para manter a umidade; os germinadores do tipo BOD foram regulados à temperatura alternada de $20-30^{\circ} \mathrm{C}(16 \mathrm{~h}$ de escuro e $8 \mathrm{~h}$ de luz, respectivamente); as contagens foram realizadas aos 14 e 30 dias após a montagem do teste, sendo os resultados expressos em percentagem de plântulas normais.

Primeira contagem de germinação: realizado conforme a metodologia prescrita para o teste de germinação, sendo o resultado expresso pela percentagem das plântulas normais, observadas na primeira avaliação, ou seja, no décimo quarto dia após o início do teste.

Comprimento da plântula: determinaram-se os comprimentos de radícula e de hipocótilo, sendo o teste realizado com quatro subamostras de 20 sementes cada, colocadas no terço superior do papel germitest, previamente umedecido com água destilada e acondicionado em forma de rolo. Estes rolos foram inseridos em sacos de polietileno e colocados no germinador com temperatura de $20-30^{\circ} \mathrm{C}$ em ausência de luz; a avaliação e as medidas foram realizadas no décimo quarto dia, quando a raiz principal foi mensurada com auxílio de uma régua milimetrada; o comprimento médio por plântula ( $\mathrm{cm} /$ plântula) foi calculado dividindo-se o somatório dos valores obtidos pelo número de sementes semeadas (Nakagawa, 1999).

Envelhecimento acelerado: foram pesadas, aproximadamente, 5 gramas de sementes de cada tratamento, as quais foram distribuídas uniformemente sobre tela de arame no interior da caixa "gerbox", contendo $40 \mathrm{ml} \mathrm{de}$ água destilada; as caixas com as respectivas tampas foram transferidas para uma câmara $\mathrm{BOD}$, regulada à temperatura de $42^{\circ} \mathrm{C}$ por 96 horas; após estes períodos as sementes foram colocadas para germinar conforme os procedimentos prescritos para o teste de germinação (Marcos Filho, 1999).

Teste de frio: para o teste foi utilizado o substrato rolo de papel, umedecido com água destilada na razão de 2,5 vezes o peso do papel, conforme metodologia proposta pelo Comitê de Vigor da International Seed Testing Association (ISTA, 1995); a seguir, foram semeadas quatro subamostras 
de 50 sementes e os rolos colocados em sacos plásticos, permanecendo em câmara regulada à temperatura constante de $10^{\circ} \mathrm{C}$ por um período de sete dias; depois, o teste foi conduzido de acordo como os procedimentos do teste de germinação.

O delineamento experimental foi inteiramente casualizado com seis tratamentos e quatro repetições. As comparações entre médias foram realizadas pelo teste de Tukey a 5\% de probabilidade.

\section{RESULTADOS E DISCUSSÃO}

\section{Características físicas:}

$\mathrm{Na}$ Figura 1 encontram-se os frutos utilizados para a extração das sementes. Os frutos $\mathrm{S}, \mathrm{F}, \mathrm{F}_{2-\mathrm{S} \text { x F }}$ e $\mathrm{F}_{2-\mathrm{Fx} \mathrm{S}}$ foram oriundos de flores hermafroditas, por isso apresentam formato piriforme e, S x F e. F x S originários de flores femininas, com formato mais arredondado.

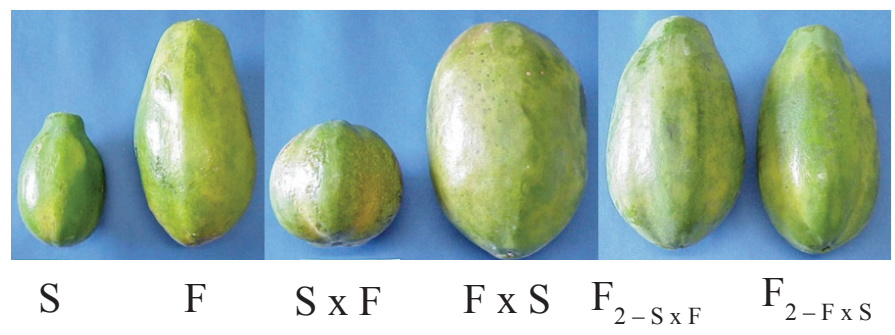

FIGURA 1 . Frutos correspondentes aos diversos tratamentos utilizados para a extração das sementes.

Todos os resultados referentes às características físicas (número de sementes por fruto, tamanho da semente e peso de mil sementes) encontram-se na Tabela 1.

TABELA 1. Valores médios do número de sementes por fruto (N.S.F.), tamanho da semente (comprimento e largura) e peso de mil sementes (P.M.S.) em função dos diferentes controles de polinização.

\begin{tabular}{llccc}
\hline Tratamentos & N.S.F. & Comprimento $(\mathrm{cm})$ & Largura $(\mathrm{cm})$ & P.M.S. $(\mathrm{g})$ \\
\hline $\mathrm{S}$ & $590,75 \mathrm{~b}$ & $0,5700 \mathrm{c}$ & $0,4288 \mathrm{c}$ & $15,43 \mathrm{~d}$ \\
$\mathrm{~F}$ & $728,00 \mathrm{ab}$ & $0,6925 \mathrm{a}$ & $0,5075 \mathrm{a}$ & $22,47 \mathrm{~b}$ \\
$\mathrm{~S} \times \mathrm{F}\left(\mathrm{F}_{1}\right)$ & $710,50 \mathrm{~b}$ & $0,5025 \mathrm{~d}$ & $0,3975 \mathrm{~d}$ & $14,13 \mathrm{e}$ \\
F x S $\left(\mathrm{F}_{1}\right)$ & $955,75 \mathrm{a}$ & $0,6800 \mathrm{a}$ & $0,5075 \mathrm{a}$ & $24,14 \mathrm{a}$ \\
$\mathrm{F}_{2-\mathrm{S} \times \mathrm{F}}$ & $806,25 \mathrm{a}$ & $0,6275 \mathrm{~b}$ & $0,4775 \mathrm{~b}$ & $18,20 \mathrm{c}$ \\
$\mathrm{F}_{2-\mathrm{F} \times \mathrm{S}}$ & $965,00 \mathrm{a}$ & $0,5625 \mathrm{c}$ & $0,4225 \mathrm{c}$ & $15,71 \mathrm{~d}$ \\
\hline C.V. $(\%)$ & 13,60 & 2,88 & 2,63 & 1,05
\end{tabular}

* Médias seguidas de mesma letra não diferem entre si pelo teste de Tukey a 5\%.

Para os genitores ( $\mathrm{S}$ e F) o número de sementes por fruto foi superior ao encontrado por Martins (2003) com frutos do mesmo grupo, porém cultivares diferentes, 353,1 para Golden e 616 para Tainung 01 .

Em relação aos tratamentos $\mathrm{S}$ x $\mathrm{F}$ e $\mathrm{F}$ x $\mathrm{S}$, o pólen não influenciou esta característica, uma vez que o número de sementes por fruto desses tratamentos foi semelhante aos dos genitores femininos. No entanto, estes tratamentos apresentam um maior número de sementes quando comparado aos genitores femininos, isto provavelmente pode ser explicado pelo fato de estes frutos serem originários de flores femininas, onde a cavidade ovariana é maior e, conseqüentemente, o número de sementes também.

Para o tamanho da semente, considerando o comprimento e a largura (Tabela 1), observa-se que não houve efeito de xênia, pois o tamanho das sementes $F_{1}(\mathrm{~S} \times \mathrm{F}$ e F x S) são semelhantes ao tamanho das sementes dos genitores femininos, neste caso, S e F, respectivamente. Para as sementes $F_{2}$ de ambos os tratamentos pode ser observado que as maiores sementes foram encontradas nos maiores frutos (de maior peso).

Verificou-se que todos os tratamentos diferiram entre si em relação ao peso de mil sementes. No entanto, pode-se constatar que as sementes $\mathrm{F}_{1}$ ( $\mathrm{S}$ x F e F x S) mostraram peso de mil sementes semelhante aos dos seus genitores femininos, o que significa que não houve efeito de xênia.

Para sementes de milho, onde o efeito de xênia já foi confirmado, vários trabalhos observaram incremento no peso 
dos grãos dependendo do polinizador utilizado (Tsai e Tsai, 1990; Weiland, 1992; Seka e Cross, 1995b; Bullant e Gallais, 1998; Mercer et al., 2002; Pereira, 2003).

Considerando a ausência de xênia para os atributos físicos (comprimento, largura e peso de mil sementes), a ação gênica se manifesta na planta $\mathrm{F}_{1}$, portanto, nas sementes $\mathrm{F}_{2}$. Observando-se os valores dos genitores e da geração $\mathrm{F}_{2}\left(\mathrm{~F}_{2-\mathrm{S} \times \mathrm{F}}\right)$, conclui-se por uma tendência de ação gênica do tipo aditiva.

\section{Qualidade Fisiológica}

Na Tabela 2 encontram-se os valores de germinação e de vigor referentes aos diferentes tratamentos. Os dados indicaram superioridade das sementes $\mathrm{F}_{1}$ em relação aos genitores quanto à germinação. Por meio desses resultados não foi possível avaliar a existência do fenômeno da xênia, em razão de os valores de germinação das sementes $F_{1}$ terem sido superiores aos dos seus genitores e não semelhantes.

TABELA 2 .Valores médios de germinação (G.) e vigor [primeira contagem (P.C.), envelhecimento acelerado (E.A.), Teste de frio (T.F.), comprimento da plântula (C.P.) e comprimento do hipocótilo (C.H.) em função dos diferentes controles de polinização.

\begin{tabular}{llcccc}
\hline Tratamentos & G. $(\%)$ & P.C. $(\%)$ & E.A. $(\%)$ & T.F. $(\%)$ & C.P. $(\mathrm{cm})$ \\
\hline $\mathrm{S}$ & $90 \mathrm{ab}$ & $89 \mathrm{a}$ & $94 \mathrm{a}$ & $91 \mathrm{ab}$ & $10,8 \mathrm{~b}$ \\
$\mathrm{~F}$ & $87 \mathrm{bc}$ & $86 \mathrm{ab}$ & $90 \mathrm{ab}$ & $87 \mathrm{~b}$ & $10,3 \mathrm{~b}$ \\
$\mathrm{~S} \times \mathrm{F}\left(\mathrm{F}_{1}\right)$ & $94 \mathrm{a}$ & $87 \mathrm{ab}$ & $99 \mathrm{a}$ & $95 \mathrm{a}$ & $12,5 \mathrm{a}$ \\
$\mathrm{F} \times \mathrm{S}\left(\mathrm{F}_{1}\right)$ & $95 \mathrm{a}$ & $87 \mathrm{ab}$ & $89 \mathrm{ab}$ & $96 \mathrm{a}$ & $12,3 \mathrm{a}$ \\
$\mathrm{F}_{2-\mathrm{S} \times \mathrm{F}}$ & $92 \mathrm{ab}$ & $86 \mathrm{ab}$ & $92 \mathrm{a}$ & $97 \mathrm{a}$ & $11,2 \mathrm{~b}$ \\
$\mathrm{~F}_{2-\mathrm{F} S}$ & $97 \mathrm{a}$ & $94 \mathrm{a}$ & $96 \mathrm{a}$ & $96 \mathrm{a}$ & $9,6 \mathrm{c}$ \\
\hline C.V. $(\%)$ & 2,25 & 3,45 & 3,54 & 2,69 & 4,17 \\
\hline
\end{tabular}

* Médias seguidas de mesma letra não diferem entre si pelo teste de Tukey a 5\%.

Verificou-se que a germinação apresentou valores elevados para todos os tratamentos, porém a germinação das sementes $\mathrm{F}_{1}\left(\mathrm{~S} \times \mathrm{F}\right.$ e F x S) e $\mathrm{F}_{2-\mathrm{F} \times \mathrm{S}}$ foi superior. Martins et al. (2006), com os mesmos genótipos referentes aos progenitores utilizados neste trabalho, Sunrise Solo $72 / 12$ e JS 12, encontraram valores de germinação de $94 \%$ e $97 \%$, respectivamente. A pequena diferença entre os resultados entre os citados trabalhos pode estar associada ao maior controle do repouso dos frutos antes da extração das sementes. Quanto às sementes $\mathrm{F}_{2}\left(\mathrm{~F}_{2-\mathrm{S} x \mathrm{~F}}\right.$ e $\left.\mathrm{F}_{2-\mathrm{F} x \mathrm{~S}}\right)$ não se verificou perda em relação à germinação. Esses resultados evidenciam a manifestação precoce da heterose para a característica germinação, uma vez que os valores de germinação das sementes $F_{1}$ foram superiores a média dos genitores. $O$ melhor desempenho das sementes $\mathrm{F}_{1}$ é resultante do efeito heterótico alcançado pelo cruzamento de linhagens que possuem boa capacidade combinatória (Gomes et al., 2000).

No trabalho desenvolvido por Marya e Jones (1983) foi observado menor número de sementes germinadas das linhagens de milho em relação às sementes híbridas, resultados estes também verificados nesta pesquisa.

Os resultados obtidos nos testes de primeira contagem do teste de germinação, de envelhecimento acelerado, de frio e de comprimento da radícula e do hipocótilo encontramse na Tabela 4. Os valores encontrados, de modo geral, foram elevados, indicando que estas sementes tinham alto vigor, evidenciado principalmente após a exposição das sementes às condições de estresse, peculiares aos testes de envelhecimento acelerado e de frio.

A verificação do efeito de xênia com base no vigor também não pode ser confirmada, devido aos valores terem sido muito semelhantes entre os genitores ( $\mathrm{S}$ e $\mathrm{F}$ ) e as sementes $\mathrm{F}_{1}$ ( $\mathrm{S} \times \mathrm{F}$ e F x S), e, em alguns casos, as sementes $\mathrm{F}_{1}$ alcançaram valores expressivamente superiores a ambos os pais. Para o vigor, a indicação mais lógica também é de uma manifestação precoce da heterose.

Como já relatado anteriormente para o teste de germinação, as sementes $\mathrm{F}_{2}\left(\mathrm{~F}_{2-\mathrm{S} \times \mathrm{F}}\right.$ e $\left.\mathrm{F}_{2-\mathrm{F} \times \mathrm{S}}\right)$ não perderam vigor quando comparadas às sementes $\mathrm{F}_{1}$ nos valores de germinação obtidos na primeira contagem e nos testes de envelhecimento acelerado e de frio. Segundo Doria et al. (1999), para o híbrido Tainung 01, esse pode ser cultivado até a geração $\mathrm{F}_{2}$ sem perda de produtividade e vigor, desde que a geração $\mathrm{F}_{2}$ seja formada a partir de sementes de mamão 
de plantas matrizes selecionadas.

As bases do vigor híbrido para qualidade fisiológica de sementes não estão totalmente elucidadas, no entanto, parece evidente o envolvimento de hormônios como auxinas (Tafuri, 1966) e giberelinas (Rood et al., 1983 e 1990). Resultados de pesquisa têm indicado que a síntese de $\alpha$-amilase e subseqüente hidrólise das reservas de sementes apresentam uma ligação entre as giberelinas e a heterose em sementes de milho (Paleg, 1965).

Outra hipótese para este crescimento mais vigoroso é a maior eficiência do sistema enzimático envolvido no processo de germinação. Causse et al. (1995) correlacionaram a maior produção de matéria seca das plântulas híbridas de milho em relação as suas linhagens parentais com a maior atividade da enzima sacarose fosfato sintetase. Entretanto, em alguns trabalhos, isto não foi verificado (Hageman et al., 1967).

Para a germinação por ocasião da primeira contagem (Tabela 7), os tratamentos $\mathrm{S}$ e $\mathrm{F}_{2-\mathrm{F} x \mathrm{~S}}$ apresentaram maiores valores, porém, não diferenciados dos demais tratamentos. Resultados semelhantes foram encontrados por Martins et al. (2006) para genótipos semelhantes aos genitores.

Para o teste de envelhecimento acelerado observou-se que os tratamentos $\mathrm{S}, \mathrm{S} \times \mathrm{F}, \mathrm{F}_{2-\mathrm{S} \times \mathrm{F}}$ e $\mathrm{F}_{2-\mathrm{F} x \mathrm{~S}}$ tiveram melhor desempenho, no entanto, também não diferiram dos demais tratamentos.

Segundo Gomes (1999), as estimativas da heterose para o teste de envelhecimento acelerado mostraram-se todas positivas, indicando que as sementes híbridas possuem potencial de armazenamento maior que as sementes das linhagens. De uma maneira geral, à medida que as sementes de linhagens são envelhecidas, há uma redução na atividade da enzima esterase, enquanto nas sementes híbridas houve uma estabilidade maior da atividade da enzima durante o envelhecimento e também na preservação da qualidade fisiológica, sugerindo que as sementes pertencentes às linhagens apresentam menor vigor em relação às sementes híbridas.

No teste de frio observou-se a superioridade na germinação das sementes $\mathrm{F}_{1}$ em relação aos genitores. Em condição de baixa temperatura, que é o princípio do teste, foram observados altos valores de germinação para todos os tratamentos, sendo os mesmos ligeiramente inferiores para o tratamento F. Valores elevados de germinação neste teste também foram encontrados por Martins et al. (2006), 97\% e $94 \%$, referentes aos genótipos dos genitores.

Em relação aos comprimentos das plântulas, foi observado maior comprimento destes em plântulas provenientes das sementes $\mathrm{F}_{1}(\mathrm{~S} \times \mathrm{F}$ e F x S). Esses resultados evidenciam que as plântulas provenientes de sementes $F_{1}$ são mais vigorosas em relação aos genitores. Vários autores têm constatado que o vigor híbrido em relação à taxa de crescimento e o potencial de produção podem estar associados à alta atividade fisiológica e bioquímica das plantas híbridas.

Mino e Inoue (1980, 1986, 1988 e 1989) relatam que o vigor híbrido, manifestado pela rápida germinação e crescimento vigoroso de plântulas, está associado às altas taxas de metabolismo de RNA, proteínas e DNA nos embriões. Em complemento a esses estudos, os autores investigaram o metabolismo de lipídeos e proteínas na germinação de sementes de milho e analisaram o metabolismo da glicose no crescimento de plântulas de milho híbrido. Os resultados indicaram que o elevado metabolismo de proteínas e lipídeos encontrados no embrião faz com que haja um crescimento mais vigoroso das células do eixo embrionário, induzindo a rápida germinação das sementes híbridas (Mino e Inoue, 1988). Em relação ao metabolismo da glicose, os resultados sugerem que a rápida ativação da função metabólica no embrião, após o começo da absorção de água, é devida à heterose manifestada no híbrido $F_{1}$, e é um dos fatores preponderantes no mecanismo pelo qual o híbrido expressa a heterose no processo de germinação. Nebiolo et al. (1983) também constataram melhor desempenho das sementes híbridas na síntese de DNA e RNA em relação às suas linhagens parentais.

Odiemah (1989) estudou o controle genético associado às características relacionadas à qualidade de sementes de milho, a partir dos testes de germinação, de condutividade elétrica, de envelhecimento acelerado, de frio e de embebição em diferentes temperaturas. $\mathrm{O}$ mesmo autor constatou que a heterose ocorreu para todos os caracteres pertinentes a qualidade fisiológica das sementes.

\section{CONCLUSÕES}

Com a ausência de xênia para os atributos físicos das sementes de mamão tais avaliações podem ser conduzidas em bancos de germoplasma, sem a necessidade do controle do pólen. Ou seja, podem-se usar frutos de polinização livre para as análises físicas de sementes.

Com a manifestação precoce da heterose nas sementes $\mathrm{F}_{1}$ para atributos fisiológicos das sementes de mamão, concluiu-se que é de extrema importância a realização da polinização controlada para tais determinações. Para avaliar o comportamento do germoplasma (diferentes genótipos per se), pode-se trabalhar com frutos autofecundados, no entanto, para avaliar o comportamento de híbridos, recomenda-se 
utilizar sementes $\mathrm{F}_{1}$.

\section{REFERÊNCIAS}

ANDRADE, J.A.C.; PEREIRA, F.C.D. Uso do efeito xênia em híbridos comerciais de milho (Zea mays L.). Revista Brasileira de Milho e Sorgo, v.4, n.3, p.65-78, 2005.

BRASIL. Ministério da Agricultura e Reforma Agrária. Regras para análise de sementes. Brasília, DF: SNDA/ DNDV/CLAV, 1992. 365p.

BULANT, C.; GALLAIS, A. Xenia effects in maize with normal endosperm: I. Importance and stability. Crop Science, v.38, p.1517-1525, 1998.

BULLANT, C.; GALLAIS, A.; MATTHYS-ROCHON, E.; PRIOUL, J.L. Xenia effects in maize with normal endosperm: II. Kernel growth and enzyme activities during grain filling. Crop Science, v.40, p.182-189, 2000.

CAUSSE, M.; ROCHER, J.P.; PELLESCHI, S. Sucrose phosphate synthase: an enzyme with heterotic activity correlated with maize growth. Crop Science, v.35, p.9951001, 1995.

CRANE, J.C.; IWAKIRI, B. Xenia and metaxenia in pistachio. HortScience, v.15, n.2, p.184-185, 1980.

DAVARYNIJAD, G.H.; NYEKI， J.; SZABO, J.H.; LAKNER, Z. Relationship between pollen donors and quality of fruit of 12 apple cultivars. In: Inter-Symp. on postharvest treatment of horticultural crops. Keeskemet. Acta Horticultura, v.368, p.344-354, 1994.

DENNEY, J.O. Xênia includes metaxenia. HortScience, v.27, n.7, p.722-728, 1992.

DORIA，R.A.; DANTAS，J.L.L.; MORALES，C.F.G.; OLIVEIRA, A.M.G. Gerações $F_{1}, F_{2}$ e $F_{3}$ do mamoeiro híbrido Tainung $\mathrm{n}^{\circ}$. III - Produção. Revista Brasileira de Fruticultura, v.21, n.1, p.12-16, 1999.

GOMES, M.S. Heterose na qualidade fisiológica de sementes de milho. 1999. 78f. Dissertação (Mestrado em Agronomia) - Universidade Federal de Lavras, Lavras.

GOMES, M.S.; VON PINHO, E.V.R.; VON PINHO, R.G.; VIEIRA, M.G.G.C. Efeito da heterose na qualidade fisiológica de sementes de milho. Revista Brasileira de Sementes, v.22, n.1, p.7-17, 2000.

HAGEMAN, R.H.; LENG, E.R.; DUDLEY, J.W. A biochemical approach to corn breading. Advances in Agronomy, v.19, p.45-85, 1967.

IMAGEJ. ImageJ for microscopy. Image processing and
analysisinJava.Disponívelem:http://www.macbiophotonics. ca/imagej/ Acesso em: 4 fev 2009.

INTERNATIONAL SEED TESTING ASSOCIATION. Handbook of vigour test methods. 3.ed. Zürich, 1995. $117 \mathrm{p}$.

MARCOS FILHO, J. Teste de envelhecimento acelerado In: KRZYZANOWSKI, F.C.; VIEIRA, R.D.; FRANÇA NETO, J.B. (Ed.). Vigor de sementes: conceitos e testes. Londrina: ABRATES, cap.3, p.1-24, 1999

MARTINS, G.N. Influência da seleção do fruto, do peso específico da semente e do armazenamento na qualidade fisiológica de sementes de mamão (Carica papaya L.). 2003. 48f. Dissertação (Mestrado em Produção Vegetal) Universidade Estadual do Norte Fluminense Darcy Ribeiro, Campos dos Goytacazes.

MARTINS, G.N.; SILVA, R.F.; PEREIRA, M.G.; ARAÚJO, E.F.; POSSE, S.C.P. Influência do repouso pós-colheita de frutos na qualidade fisiológica de mamão. Revista Brasileira de Sementes, v.28, n.2, p.142-146, 2006.

MARYA, B.; JONES, D.A. The genetics of maize (Zea mays L.) growing at low temperatures. Germination of inbred lines and their $\mathrm{F}_{1}$ 's. Euphytica, v.32, n.3, p.535-542, 1983.

MERCER, J.R.; RAMALHO, M.A.P.; RAPOSO, F.V. Implicações do fenômeno de xênia nos programas de melhoramento de milho. Ciência Agrotécnica, v.26, n.6, p.1338-1343, nov./dez., 2002.

MINO, M.; INOUE, M. DNA synthesis and nuclease activity during germination of a heterotic F1 hybrid of maize. Canadian Journal Botany, v. 67, n.1, p.73-75, 1989.

MINO, M.; INOUE, M. Heterotic viability under the treatment of cycloheximide and 6-methylpurine in germinating maize kernels. Japan Journal Breeding, v.36, p.240-247, 1986.

MINO, M.; INOUE, M. Hybrid vigor in relation to lipid and protein metabolism in germinating maize kernels. Japan Journal Breeding, v.38, p.428-436, 1988.

MINO, M.; INOUE, M. RNA and protein synthesis during germination process of $\mathrm{F} 1$ hybrid and its parental inbred lines of maize. Plant Science Letters, v.20, p.7-13, 1980.

NAKAGAWA, J. Teste de vigor baseados no desempenho das plântulas. In: KRZYZANOWSKI, F.C.; VIEIRA, R.D.; FRANÇA NETO, J.B. (Ed.). Vigor de sementes: conceitos e testes. Londrina: ABRATES, 1999. cap.2, p.1-24

NEBIOLO, C.M.; KACZAMARCZYK, W.J.; ULRICH, V. Manifestation of hybrid vigor in RNA synthesis parameters by corn seedling protoplasts in the presence and absence of gibberelic acid. Plant Science Letters, v.28, p.195-206, 
1983.

ODIEMAH, M. Quantitative inheritance of seed quality characteristics in maize (Zea mays L.). Cereal Research Communications, v.17, n.1, p.245-251, 1989.

PALEG, L.G. Physiological effects of gibberellins. Annual Review of Plant Physiology, v.16, p.291-322, 1965.

PEREIRA, F.C.D. Uso do efeito em híbridos comerciais de milho (Zea mays L.). 2003. 51f. Dissertação (Mestrado em Agronomia) Faculdade de Engenharia de Ilha Solteira, Universidade Estadual Paulista, Ilha Solteira.

RAHEMI, M. MOJAMAD, J.D. Effects of pollen source on nut and kernel characteristics of hazelnut. Acta Horticulturae, n.550, p.371-376, 2001.

ROOD, S.B.; BLAKE, T.J.; PHARIS, R.P. Gibberellins and heterosis in maize. Response to gibberellic acid and metabolism of $\left[{ }^{3} \mathrm{H} \mathrm{GA}_{20}\right.$. Plant Physiology, v.17, n.3, p.645$651,1983$.

ROOD, S.B.; BUZZELL, R.I.; MAJOR, D.J. Gibberellins and heterosis in maize: quantitative relationships. Crop Science, v.30, n.2, p.281-286, 1990.

SEKA, D.; CROSS, H.Z. Xenia and maternal effects on maize agronomic traits at three plant densities. Crop Science, v.35, n.1, p.86-90, 1995 b.

SEKA, D.; CROSS, H.Z. Xenia and maternal effects on maize kernel development. Crop Science, v.35, n.1, p.8085, 1995a.

TAFURI, F. IAA determination in the kernels of four lines of corn and their hybrids. Phytochemistry, v.5, n.4, p.9991003, 1966.

TSAI, C.L.; TSAI, C.Y. Endosperm modified by crosspollinating maize to induce changes in dry matter and nitrogen accumulation. Crop Science, , v.30, p.804-808, 1990.

WEILAND, R.T. Cross-pollination effects on maize (Zea mays L.) hybrid yields. Canadian Journal of Plant Science, v.72, p.27-33, 1992. 